\title{
Speed Estimation of Adaptive Stator-flux-vector-controlled Induction Motor Drive Based on Particle Swarm Optimization Algorithm
}

\author{
Yung-Chang Luo, Sheng-Hong Pei, Ying-Piao Kuo, and Cheng-Tao Tsai \\ Department of Electrical Engineering, National Chin-Yi University of Technology, \\ No. 57, Sec. 2, Zhongshan Rd, Taiping Dist, Taichung 41170, Taiwan (ROC)
}

(Received May 9, 2019; accepted February 10, 2020)

Keywords: speed estimation, stator flux vector control (SFVC), model reference adaptive system (MRAS), particle swarm optimization (PSO) algorithm, field weakening

An adaptive synchronous speed estimation scheme is proposed for the speed estimation of a stator-flux-vector-controlled (SFVC) induction motor (IM) drive. An SFVC IM drive was established according to the current and flux of the stator, and the stator current was obtained from an IM by using Hall effect current sensors. A model reference adaptive system (MRAS) was utilized to design the synchronous speed identification scheme based on the reactive power, and the estimated rotor speed was obtained by subtracting the slip speed from the estimated synchronous speed. The adaptation mechanism of the MRAS was designed using the particle swarm optimization (PSO) algorithm. The available operation speed was extended to the constant-power mode by applying the field-weakening technique. The MATLAB $\backslash$ Simulink ${ }^{\circledR}$ toolbox was used to simulate this system, and all the control algorithms were realized using a Texas Instruments 6713-and-F2812 DSP card to generate pulse-width modulation signals for the power stage to actuate the IM. Both the simulation and experiment results (including the estimated rotor speed, stator current, electromagnetic torque, and stator flux locus) confirm the effectiveness of the proposed system and validate the proposed approach.

\section{Introduction}

Intelligent manufacturing technology requires numerous high-performance motors to actuate machine tools. Induction motors (IMs) are commonly adopted because of their robustness, few maintenance requirements, and suitability for use under hostile environmental conditions. However, the nonlinear coupling and time-varying mathematical models of an IM drive make its control more difficult than that of a DC motor drive. By applying the flux vector control (FVC) theory of IMs, ${ }^{(1)}$ the complicated mathematical model of an IM can be converted into a flux-current component and torque-current component. Both components are orthogonal and can be separately controlled. This condition is analogous to a separately excited DC motor, and the maximum torque-to-current ratio can be attained. The FVC methods of an IM drive can be classified into rotor, stator, and air-gap types. In the rotor type, the stator current and 
rotor flux are selected as the state variables. In the stator type, the current and flux of the stator are selected as the state variables. In the air-gap type, the stator current and air-gap flux are selected as the state variables. The implementation of an FVC IM drive requires a rotor position sensor, such as an encoder, to detect the shaft position. This sensor, however, reduces the robustness of a motor and is unsuitable for hostile conditions. Hence, the development of speed estimation FVC IM drives in place of conventional FVC IM drives (rotor position sensor types) is required. In the literature, speed estimation methods for FVC IM drives have been presented: speed identification by an adaptive control system, ${ }^{(2-4)}$ speed estimation by the application of a neural network or fuzzy logic control approach, ${ }^{(5,6)}$ speed adjustment by flux estimation, ${ }^{(7-10)}$ and speed determination from an extended Kalman filter. ${ }^{(11-13)}$ However, an adaptive control system easily traps a chattering effect with large control variables; a neural network or fuzzy logic control approach requires trial-and-error training procedures, iterative computations, a large amount of training data, network parameter assignment, and fuzzy rules; flux estimation requires the construction of an accurate plant model; and an extended Kalman filter requires a large amount of computation and memory. These requirements of the above methods will increase the design cycle and cost.

Variable-speed IM drives contain a constant-torque mode and the constant-power mode. In the constant-torque mode, the operation speed ranges from zero to the base speed, the flux command is set at the base value, and the available output power is proportional to the motor speed. In the constant-power mode, the operation speed ranges from the base speed to the maximum speed (two times the base speed), the flux command decreases with increasing motor speed, and the increase in the motor speed decreases the available torque. In this study, a stator-flux-vector-controlled (SFVC) IM drive was established according to the current and flux of the stator. A synchronous speed identification scheme was developed according to the model reference adaptive system (MRAS) theory based on the reactive power of an IM, and the adaptation mechanism of the MRAS was designed using the particle swarm optimization (PSO) algorithm. The rotor speed was estimated by subtracting the estimated slip speed from the estimated synchronous speed. The available operation speed range can be extended to the constant-power mode by applying the field-weakening technique. Hall effect current sensors were used to measure the IM stator current in the implementation of this speed estimation of adaptive SFVC IM drive.

This paper has four sections. In Sect. 1, the research background, motivation, and a literature review of speed estimation methods for FVC IM drives are presented. The decoupled SFVC IM drive system used in this study is covered in Sect. 2. The MRAS synchronous speed identification scheme based on the reactive power and the adaptation mechanism of the MRAS designed using the PSO algorithm are described in Sect. 3. Simulations and experiments are discussed in Sect. 4.

\section{SFVC IM Drive}

The stator and rotor voltage vector equations of an IM in the synchronous reference coordinate frame from Ref. 14 are given as 


$$
\begin{gathered}
\left(j \omega_{e}+p\right) \vec{\lambda}_{s}^{e}+R_{s} \vec{i}_{s}^{e}=\vec{v}_{s}^{e}, \\
\left(R_{r}+j \omega_{s l} L_{r}+L_{r} p\right) \vec{\lambda}_{s}^{e}-L_{s}\left(R_{r}+j \sigma L_{r} \omega_{s l}+\sigma L_{r} p\right) \vec{i}_{s}^{e}=0,
\end{gathered}
$$

where $j$ is the imaginary unit, $\vec{v}_{s}^{e}=v_{d s}^{e}+j v_{q s}^{e}$ and $\vec{i}_{s}^{e}=i_{d s}^{e}+j i i_{q s}^{e}$ are the stator voltage and current vectors, $\vec{\lambda}_{s}^{e}=\lambda_{d s}^{e}+j \lambda_{q s}^{e}$ is the stator flux vector, $R_{s}$ and $R_{r}$ are the stator and rotor resistances, $L_{s}$ and $L_{r}$ are the stator and rotor inductances, $L_{m}$ is the mutual inductance between the stator and rotor, $\sigma=1-L_{m}^{2} /\left(L_{s} L_{r}\right)$ is the leakage inductance coefficient, $\omega_{e}$ is the speed of the synchronous reference coordinate frame, $\omega_{r}$ is the electric speed of the rotor, $\omega_{s l}=\omega_{e}-\omega_{r}$ is the slip speed, and $p=d / d t$ is the differential operator, respectively.

Under an SFVC condition, set $\lambda_{q s}^{e}=0$ in Eq. (2), and the slip speed and the $d$-axis stator flux are respectively estimated as

$$
\begin{gathered}
\hat{\omega}_{s l}=\frac{\left(1+\sigma \tau_{r} s\right) L_{s} i_{q s}^{e}}{\tau_{r}\left(\lambda_{d s}^{e}-\sigma L_{s} i_{d s}^{e}\right)}, \\
\frac{1+\tau_{r} s}{\left(1+\sigma \tau_{r} s\right) L_{s}} \hat{\lambda}_{d s}^{e}=i_{d s}^{e}-\frac{\sigma \tau_{r} \omega_{s l}}{\left(1+\tau_{r} s\right)} i_{q s}^{e},
\end{gathered}
$$

where ${ }^{\wedge}$ stands for the estimated value, $\tau_{r}=L_{r} / R_{r}$ is the rotor time constant, and $s$ is the Laplace operator.

The second term on the right of Eq. (4) is the coupling component with relation to the $q$-axis stator current. Using this term, the feedforward compensation can be defined as

$$
i_{d_{-} q c}^{e}=\frac{\sigma \tau_{r} \omega_{s l}}{\left(1+\tau_{r} s\right)} i_{q s}^{e}
$$

Hence, the linear relationship between the estimated $d$-axis stator flux and the $d$-axis stator current can be derived as

$$
\hat{\lambda}_{d s}^{e}=\frac{\left(1+\sigma \tau_{r} s\right) L_{s}}{1+\tau_{r} s} i_{d s}^{e}
$$

The generated electromagnetic torque of an IM under an SFVC condition is derived as

$$
T_{e}=\frac{3 P}{4} i_{q s}^{e} \hat{\lambda}_{d s}^{e},
$$

where $P$ denotes the number of motor poles. In Eq. (7), both the $q$-axis stator current and the estimated $d$-axis stator flux are orthogonal. The generated electromagnetic torque of an IM is dominated by the $q$-axis stator current, and the maximum torque-to-current ratio can be achieved. The mechanical equation of an IM is given by 


$$
T_{e}=T_{L}+B_{m} \omega_{r m}+J_{m} p \omega_{r m}
$$

where $T_{L}$ is the load torque, $B_{m}$ is the viscous friction coefficient, $J_{m}$ is the inertia of the motor, and $\omega_{r m}=(2 / P) \omega_{r}$ is the mechanical speed of the motor shaft.

Furthermore, setting $\lambda_{q s}^{e}=0$ in Eq. (1), the $d$-axis and $q$-axis stator voltage equations under an SFVC are respectively obtained as

$$
\begin{aligned}
& v_{d s}^{e}=R_{s} i_{d s}^{e}+p \hat{\lambda}_{d s}^{e}, \\
& v_{q s}^{e}=R_{s} i_{q s}^{e}+\omega_{e} \hat{\lambda}_{d s}^{e} .
\end{aligned}
$$

Equation (9) shows the inherently linear relationship of the $d$-axis stator current control loop, and the second term on the right of Eq. (10) is the coupling component with relation to the estimated $d$-axis stator flux. Therefore, the feedforward compensation can be defined as $\omega_{e} \hat{\lambda}_{d s}^{e}$, and the linear relationship of the $q$-axis stator current control loop can be realized.

The voltage commands of the $d$-axis and $q$-axis stator current control loops are respectively derived as

$$
\begin{gathered}
v_{d s}^{e^{*}}=v_{d s}^{e^{\prime},} \\
v_{q s}^{e^{*}}=v_{q s}^{e^{\prime}}+\omega_{e} \hat{\lambda}_{d s}^{e},
\end{gathered}
$$

where $v_{d s}^{e^{\prime}}$ and $v_{q s}^{e^{\prime}}$ are the outputs of the $d$-axis and $q$-axis stator current controllers, respectively.

From Eqs. (9) and (6), and with the decoupling of Eq. (10), the plants of the $d$-axis and $q$-axis stator current control loops can be respectively obtained as

$$
\begin{gathered}
G_{p_{-} i_{d s}}(s)=\frac{1+\tau_{r} s}{R_{S}+\left(\tau_{r} R_{S}+L_{S}\right) s+\sigma \tau_{r} L_{S} s^{2}}, \\
G_{p_{-} i_{q s}}(s)=\frac{1}{R_{S}} .
\end{gathered}
$$

Since the bandwidths of the inner stator current control loops are much higher than those of the flux control loop and speed control loop, the closed-loop gain of the stator current control loops can be regarded as a unit. ${ }^{(14)}$ According to Eqs. (6) and (8), the plant of the flux control loop and the plant of the speed control loop are respectively given by

$$
G_{p_{-} f l u x}(s)=\frac{\left(1+\sigma \tau_{r} s\right) L_{s}}{1+\tau_{r} s},
$$




$$
G_{p_{-} \text {speed }}(s)=\frac{1}{B_{m}+J_{m} s} .
$$

A block diagram of IM's linear control under the SFVC condition is shown in Fig. 1. Here, the paired parameters $\left(K_{p s}, K_{i s}\right),\left(K_{p f}, K_{i f}\right),\left(K_{p d}, K_{i d}\right)$, and $\left(K_{p q}, K_{i q}\right)$ are the proportional and integral (PI) gains of the speed controller, flux controller, $d$-axis stator-current controller, and $q$-axis stator-current controller, respectively.

\section{Speed Estimation Scheme of SFVC IM Drive}

In the speed estimation scheme of the SFVC IM drive, the feedback speed is replaced by a signal of the estimated speed, which is derived from the designed MRAS synchronous speed identification scheme based on the reactive power.

\subsection{MRAS speed estimation scheme based on reactive power}

In the proposed speed estimation SFVC IM drive, the estimated synchronous speed is derived from an MRAS speed estimation scheme based on the reactive power of an IM, and the estimated rotor speed is obtained by subtracting the slip speed from the estimated synchronous speed. This approach is guaranteed to realize the best performance of SFVC IM for speed estimation.

According to Eq. (1), the $d$-axis and $q$-axis stator voltages are, respectively,

$$
\begin{aligned}
& v_{d s}^{e}=R_{s} i_{d s}^{e}+p \lambda_{d s}^{e}-\omega_{e} \lambda_{q s}^{e}, \\
& v_{q s}^{e}=R_{s} i_{q s}^{e}+p \lambda_{q s}^{e}+\omega_{e} \lambda_{d s}^{e} .
\end{aligned}
$$

The absorbed reactive power of an IM obtained from the power source can be expressed as

$$
Q=v_{q s}^{e} i_{d s}^{e}-v_{d s}^{e} i_{q s}^{e}
$$

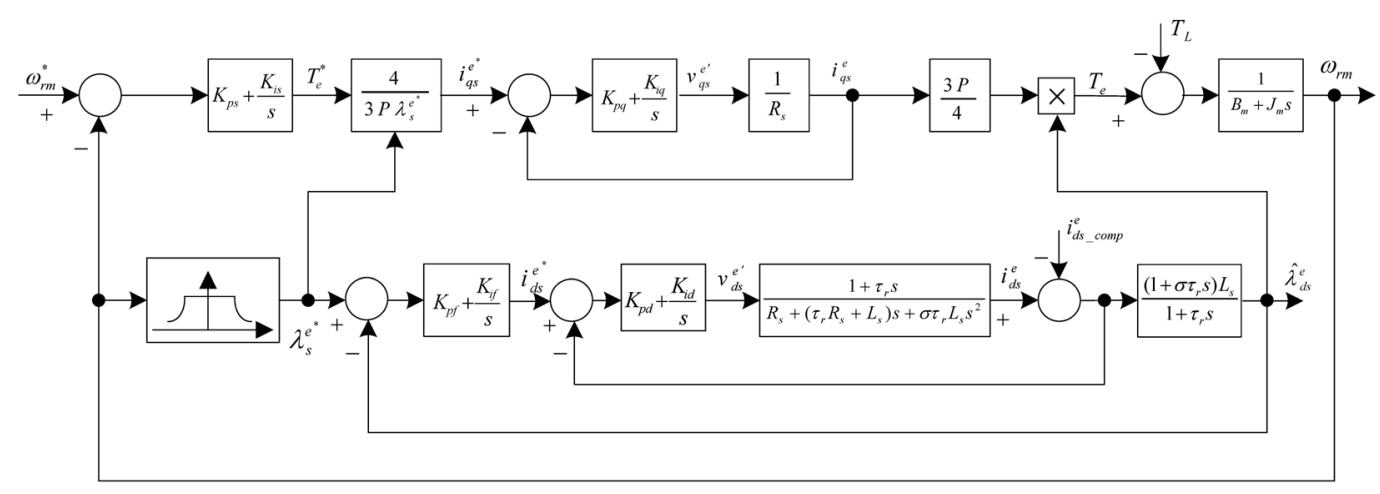

Fig. 1. Block diagram of linear control SFVC IM drive. 
Substituting Eqs. (17) and (18) into Eq. (19) and setting $\lambda_{q s}^{e}=0$, under an SFVC condition, the absorbed reactive power of an IM can also be expressed as

$$
Q^{\prime}=\hat{\omega}_{e} i_{d s}^{e} \hat{\lambda}_{d s}^{e}-i_{q s}^{e} p \hat{\lambda}_{d s}^{e}
$$

According to MRAS theory, ${ }^{(15)}$ Eq. (19) can be used as the reference model because it does not contain the estimated synchronous speed $\hat{\omega}_{e}$. Equation (20), which contains $\hat{\omega}_{e}$, can be used as the adjustable model. The difference between the reference model and the adjustable model is fed to an adaptation mechanism to identify the estimated synchronous speed $\hat{\omega}_{e}$, and the adaptation mechanism of the MRAS was designed using the PSO algorithm. The proposed MRAS synchronous speed identification scheme based on the reactive power is shown in Fig. 2. Here, the current and voltage of the stator were obtained from an IM using isolation voltage sensors and Hall effect current sensors.

Using the MRAS synchronous speed identification scheme with the PSO algorithm adaptation mechanism and Eq. (3), the rotor speed of the proposed speed estimation adaptive SFVC IM drive can be estimated as

$$
\hat{\omega}_{r}=\hat{\omega}_{e}-\hat{\omega}_{s l}
$$

\subsection{PSO algorithm adaptation mechanism design}

The PSO algorithm was used to design the adaptation mechanism of the MRAS synchronous speed identification scheme for the speed estimation SVFC IM drive because the algorithm is suitable for irregular and time-varying conditions. The PSO algorithm is a random searching algorithm based on swarm intelligence and imitates the foraging of a bird flock. ${ }^{(16)}$ The original PSO algorithm has the convergence to local solutions, and some modified methods have been developed, such as the spider monkey, dynamic system tracking, inertia weight, and constriction factor algorithms. ${ }^{(17,18)}$ In this system, the inertia weight method was used, which compared with other intelligent search methods, ${ }^{(19,20)}$ has the advantages of few parameters, rapid convergence, and suitability for various conditions. ${ }^{(21)}$

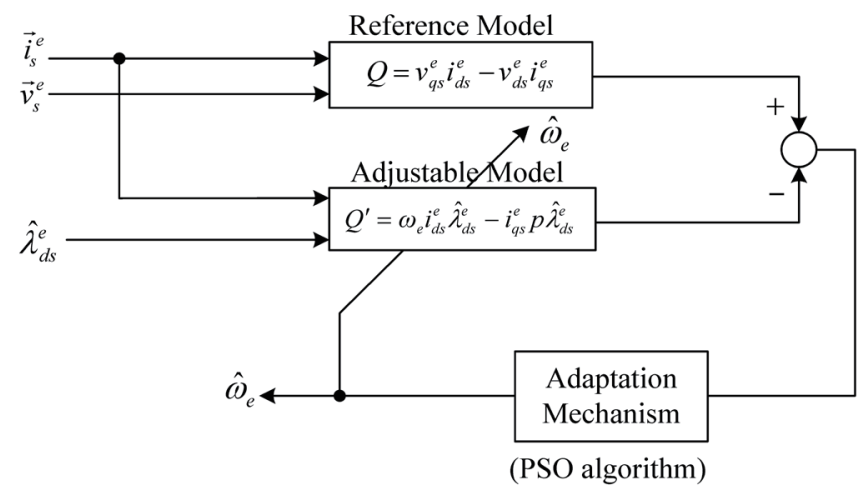

Fig. 2. MRAS synchronous speed identification scheme based on the reactive power. 
The inertia weight PSO algorithm is a reiteration recurrent procedure. First, a group of particles are randomly produced, and the current fitness value of each particle is computed to determine whether it is better than the best fitness value of an individual particle. Then, the velocity and position of each particle are updated, and the new fitness value of each particle is also computed. The updated velocity and position formulas of the particle are

$$
\begin{gathered}
V_{i}(k+1)=w \cdot V_{i}(k)+C_{1} \cdot \text { rand } \cdot\left(P_{\text {best }}-x_{i}\right)+C_{2} \cdot \operatorname{rand} \cdot\left(G_{\text {best }}-x_{i}\right), \\
x_{i}(k+1)=x_{i}(k)+V_{i}(k+1),
\end{gathered}
$$

where $V_{i}(k)$ and $V_{i}(k+1)$ are the current and next velocity of the particle, $x_{i}(k)$ and $x_{i}(k+1)$ are the current and next position of the particle, $P_{\text {best }}$ is the best position of the individual particle, $G_{b e s t}$ is the best position of the particle swarm, $w$ is the weighting factor, $C_{1}$ and $C_{2}$ are the learning factors of the individual particle and swarm, and rand is a uniformly distributed random variable over [0,1], respectively.

Figure 3 shows the two-dimensional relationship between the velocity and position search spaces for a particle, and a flow chart of the proposed inertia weight PSO algorithm is shown in Fig. 4.

A block diagram of the proposed speed estimation of adaptive SFVC IM drive based on the inertia weight PSO algorithm is shown in Fig. 5. The system includes a speed controller, flux controller, $q$-axis and $d$-axis stator current controllers, $d$-axis flux decoupling, $q$-axis voltage decoupling, flux command calculation, $d$-axis flux estimation, slip speed estimation, coordinate transformation, and MRAS synchronous speed identification based on the inertia weight PSO algorithm. In this study, the root-locus method was used to design the PI-type controllers for the speed control loop, flux control loop, and $d$-axis and $q$-axis stator current control loops.

The proportional gain $\left(K_{p}\right)$, integral gain $\left(K_{i}\right)$, and bandwidth $(B . W)$ for the four PI-type controllers are shown in Table 1. The root locus and Bode plot of the designed flux control loop are respectively shown in Figs. 6 and 7.

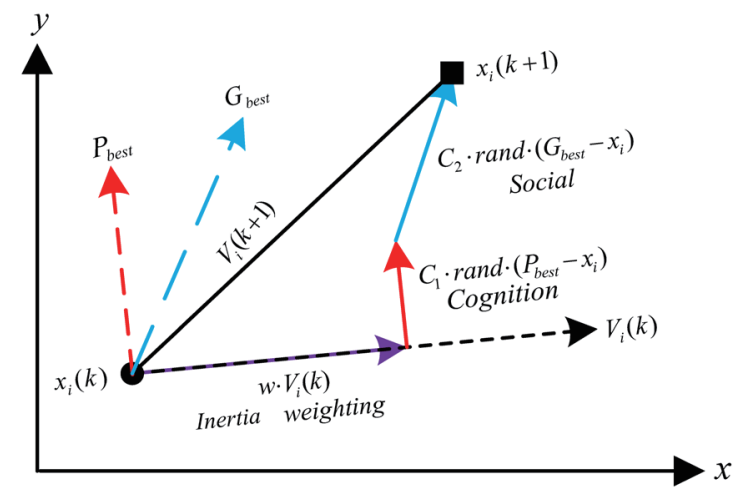

Fig. 3. (Color online) Two-dimensional relationship between the velocity and position search spaces for a particle. 


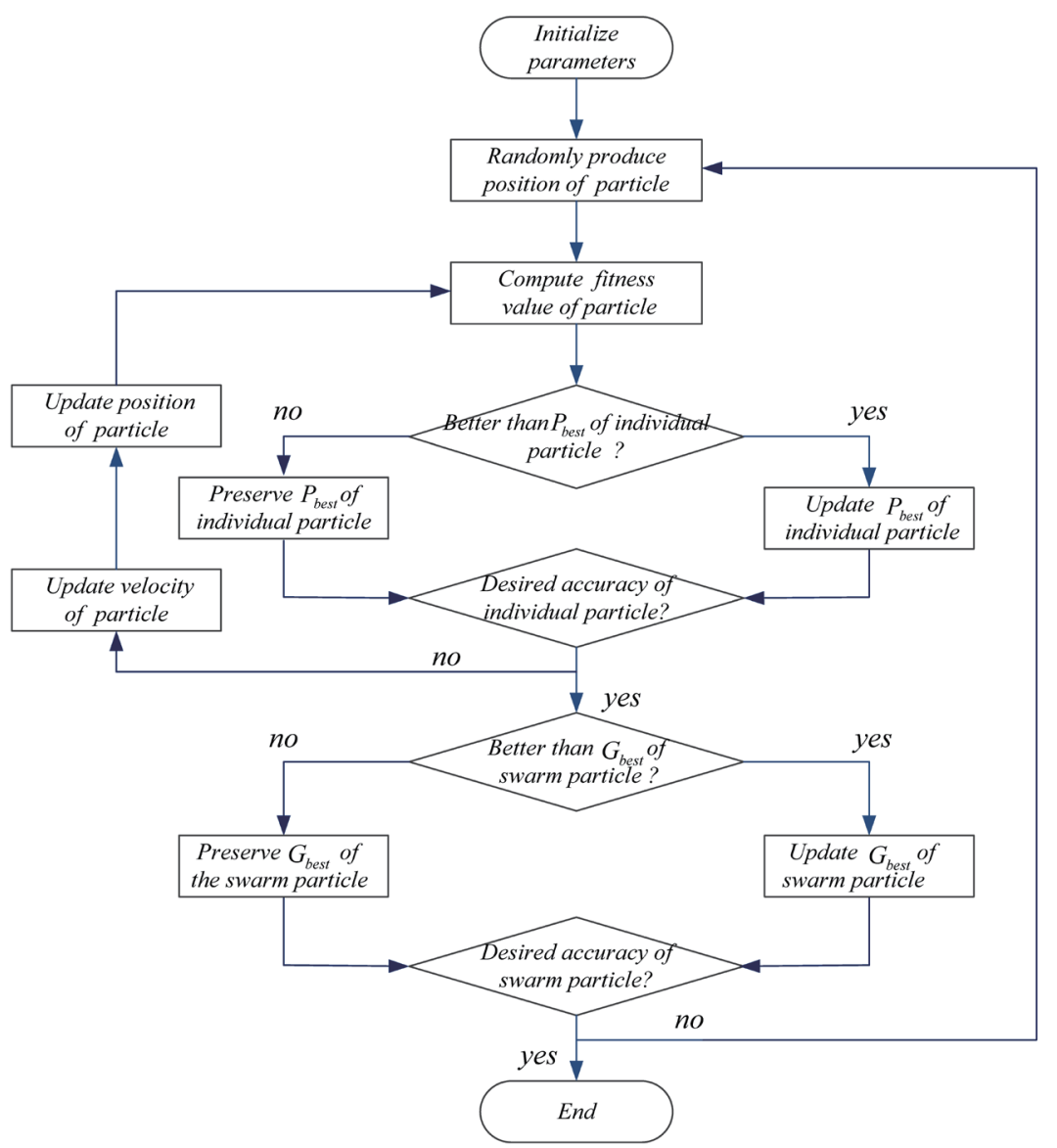

Fig. 4. Flow chart of the proposed inertia weight PSO algorithm.

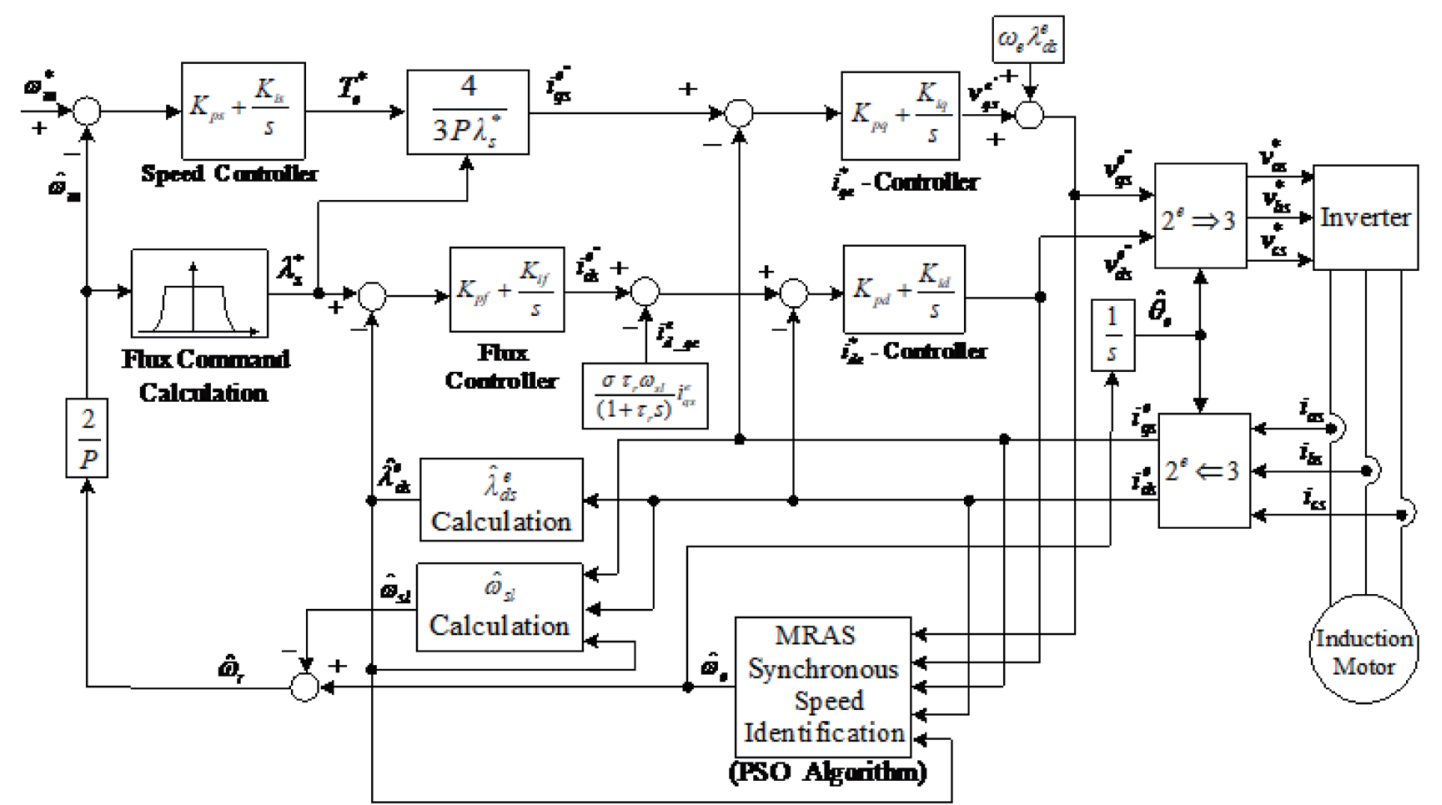

Fig. 5. Block diagram of the proposed speed estimation of adaptive SFVC IM drive based on the weight PSO algorithm. 
Table 1

Controller parameters and their bandwidth.

\begin{tabular}{llcc}
\hline & $K_{p}$ & $K_{i}$ & $B . W$ \\
\hline Speed controller & 0.035 & 0.105 & 6.11 \\
Flux controller & 1.4 & 16.8 & 17.2 \\
$d$-axis stator current controller & 5 & 6000 & 2610 \\
$q$-axis stator current controller & 12 & 10200 & 1100 \\
\hline
\end{tabular}

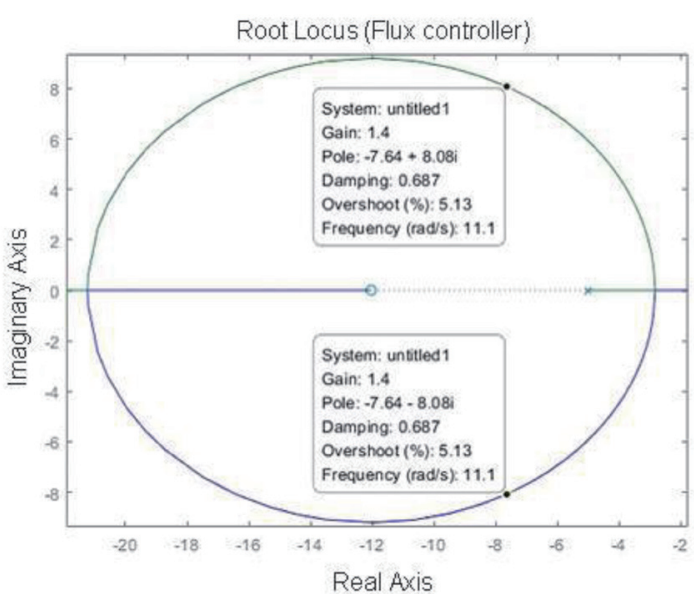

Fig. 6. (Color online) Root locus of the flux controller.

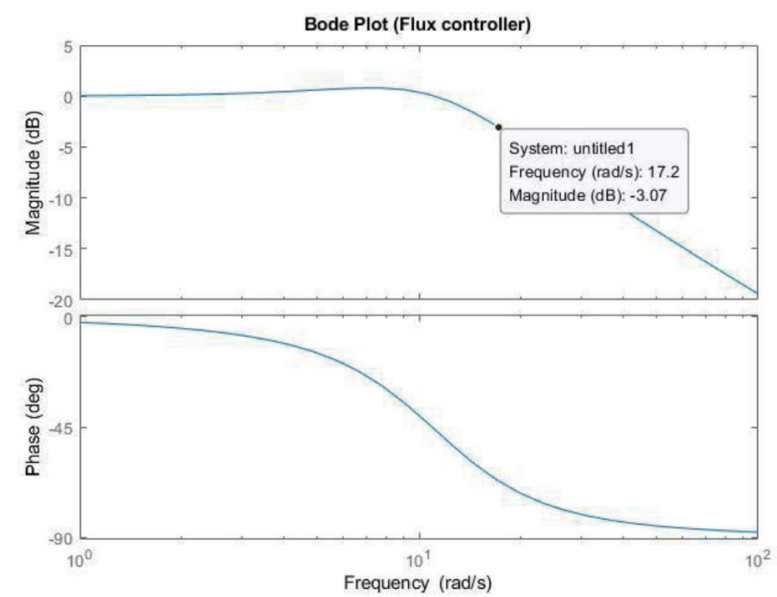

Fig. 7. (Color online) Bode plot of the flux controller.

Table 2

Parameters of the IM used in the experiment.

\begin{tabular}{lc}
\hline Base freq. $(\mathrm{Hz})$ & 60 \\
Base speed $(\mathrm{rpm})$ & 1680 \\
Poles & 4 \\
$R_{S}(\Omega)$ & 2.85 \\
$R_{r}(\Omega)$ & 2.3433 \\
$L_{s}(\mathrm{H})$ & 0.1967 \\
$L_{r}(\mathrm{H})$ & 0.1967 \\
$L_{m}(\mathrm{H})$ & 0.1886 \\
$J_{m}\left(\mathrm{Nt}-\mathrm{m}-\mathrm{s}^{2} / \mathrm{rad}\right)$ & 0.009 \\
$B_{m}\left(\mathrm{Nt}-\mathrm{m}-\mathrm{s}^{2} / \mathrm{rad}\right)$ & 0.00825 \\
\hline
\end{tabular}

\section{Simulation and Experiment}

A standard three-phase, $220 \mathrm{~V}, 0.75 \mathrm{~kW}, \Delta$-connected, squirrel-cage IM was used in the experiments to confirm the effectiveness of the proposed speed estimation of adaptive SFVC IM drive based on the PSO algorithm. The IM parameters are listed in Table 2. In a running cycle, the sequence of speed commands is as follows: forward-direction acceleration from $t=0 \mathrm{~s}$ to $t=1 \mathrm{~s}$; forward-direction steady-state operation during $1 \leq t \leq 4 \mathrm{~s}$; forward-direction braking to reach zero speed in the interval $4 \leq t \leq 5 \mathrm{~s}$; reverse-direction acceleration from $t=5 \mathrm{~s}$ to $t=6 \mathrm{~s}$; reverse-direction steady-state operation during $6 \leq t \leq 9 \mathrm{~s}$; reverse-direction braking to reach zero speed in the interval $9 \leq t \leq 10 \mathrm{~s}$. The simulated and measured responses in the first running cycle are shown in Figs. 8-13. Each figure contains six responses: the estimated 
(a)

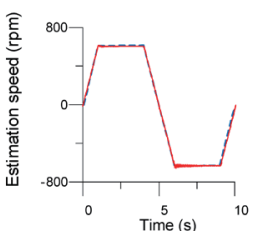

(b)

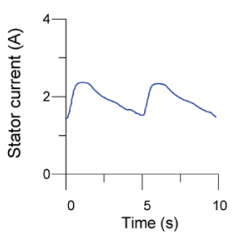

(c)

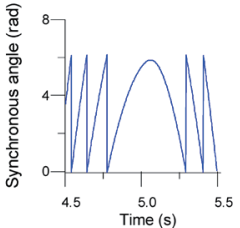

(d)

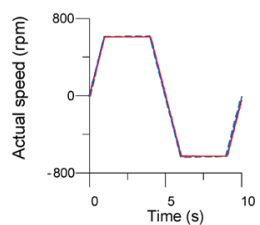

(e)

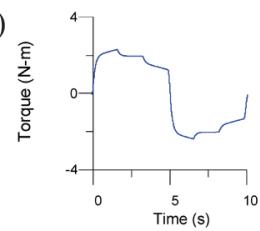

(f)

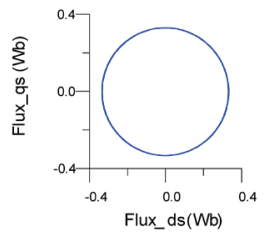

Fig. 8. (Color online) Simulated responses of the proposed speed estimation of adaptive SFVC IM drive with $2 \mathrm{~N}-\mathrm{m}$ load for steady-state speed command $\pm 600 \mathrm{rpm}$. (a) Command speed (blue line) and estimated rotor speed (red line), (b) command speed (blue line) and actual rotor speed (red line), (c) stator current, (d) electromagnetic torque, (e) estimated synchronous angle position, (f) stator flux locus.

(a)

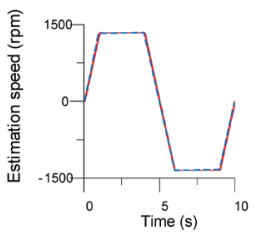

(b)

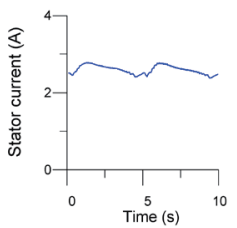

(c)

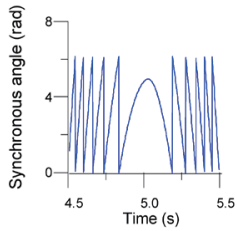

(d)

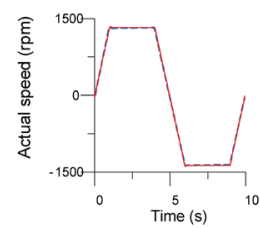

(e)

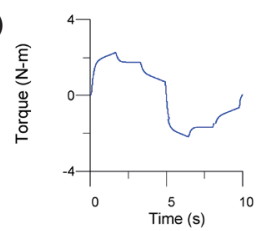

(f)

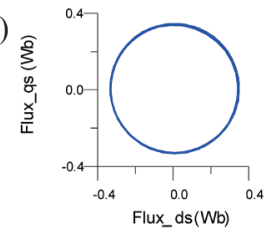

Fig. 10. (Color online) Simulated responses of the proposed speed estimation of adaptive SFVC IM drive with $2 \mathrm{~N}$-m load for steady-state speed command $\pm 1200 \mathrm{rpm}$. (a) Command speed (blue line) and estimated rotor speed (red line), (b) command speed (blue line) and actual rotor speed (red line), (c) stator current, (d) electromagnetic torque, (e) estimated synchronous angle position, (f) stator flux locus.

(a) $\stackrel{\text { ह }}{\underline{\underline{g}}}$

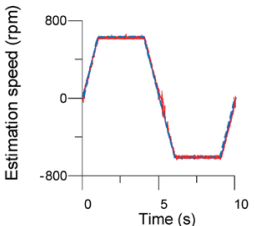

(d)

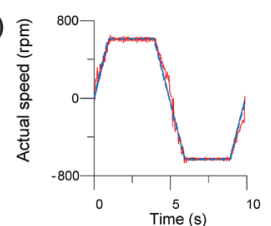

(b)

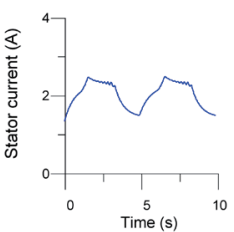

(e)

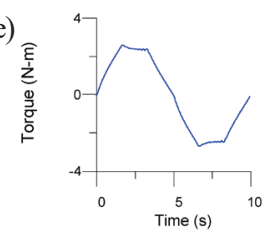

(c)

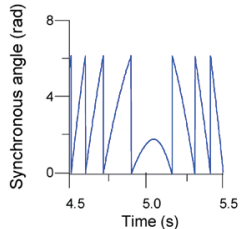

Fig. 9. (Color online) Measured responses of the proposed speed estimation of adaptive SFVC IM drive with $2 \mathrm{~N}-\mathrm{m}$ load for steady-state speed command $\pm 600 \mathrm{rpm}$. (a) Command speed (blue line) and estimated rotor speed (red line), (b) command speed (blue line) and actual rotor speed (red line), (c) stator current, (d) electromagnetic torque, (e) estimated synchronous angle position, (f) stator flux locus.

(a)

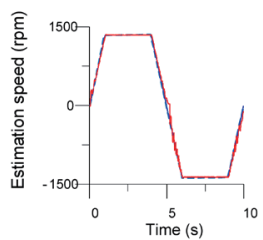

(b)

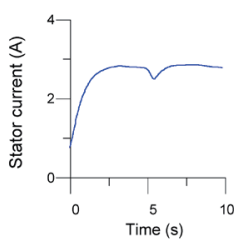

(c)

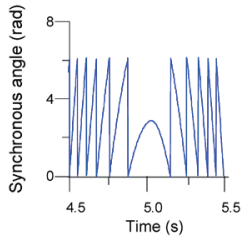

(d)

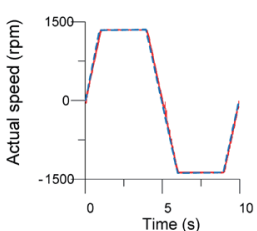

(e)

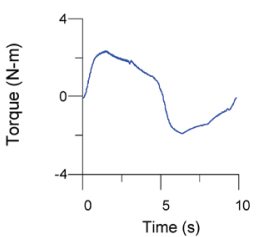

(f)

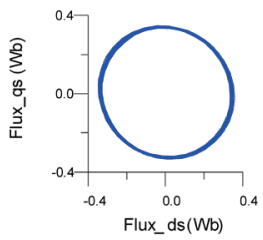

Fig. 11. (Color online) Measured responses of the proposed speed estimation of adaptive SFVC IM drive with $2 \mathrm{~N}-\mathrm{m}$ load for steady-state speed command $\pm 1200 \mathrm{rpm}$. (a) Command speed (blue line) and estimated rotor speed (red line), (b) command speed (blue line) and actual rotor speed (red line), (c) stator current, (d) electromagnetic torque, (e) estimated synchronous angle position, (f) stator flux locus. 
(a)

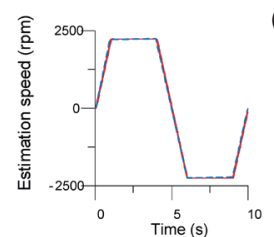

(b)

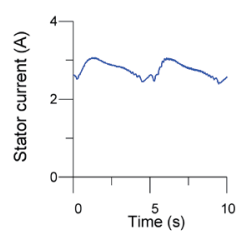

(c)

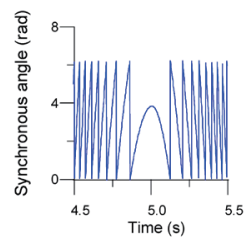

(d)

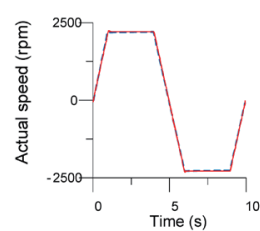

(e)

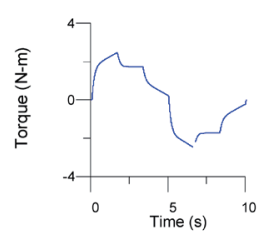

(f)

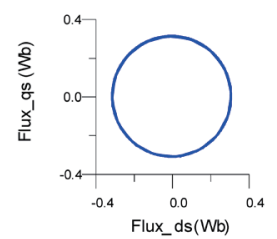

Fig. 12. (Color online) Simulated responses of the proposed speed estimation of adaptive SFVC IM drive with $2 \mathrm{~N}-\mathrm{m}$ load for steady-state speed command $\pm 2200 \mathrm{rpm}$. (a) Command speed (blue line) and estimated rotor speed (red line), (b) command speed (blue line) and actual rotor speed (red line), (c) stator current, (d) electromagnetic torque, (e) estimated synchronous angle position, (f) stator flux locus.

(a)

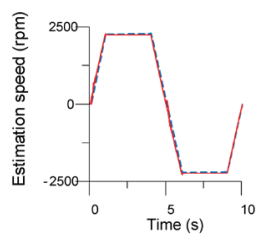

(d)

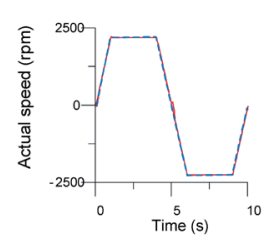

(b)

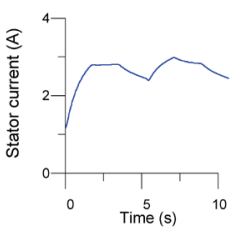

(e)

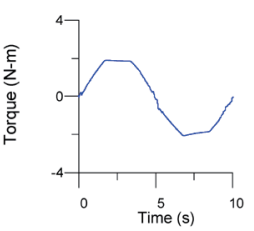

(c)

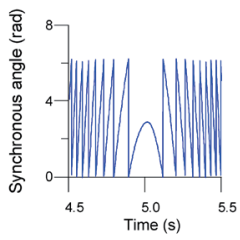

(f)

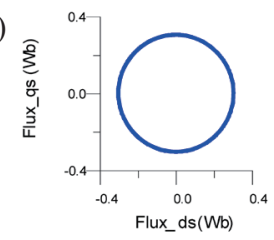

Fig. 13. (Color online) Measured responses of the proposed speed estimation of adaptive SFVC IM drive with $2 \mathrm{~N}-\mathrm{m}$ load for steady-state speed command $\pm 2200 \mathrm{rpm}$. (a) Command speed (blue line) and estimated rotor speed (red line), (b) command speed (blue line) and actual rotor speed (red line), (c) stator current, (d) electromagnetic torque, (e) estimated synchronous angle position, (f) stator flux locus.

rotor speed, actual rotor speed, stator current, electromagnetic torque, estimated synchronous angle position, and stator flux locus. The simulated and measured responses with a $2 \mathrm{~N}-\mathrm{m}$ load for reversible steady-state speed commands $\pm 600 \mathrm{rpm}, \pm 1200 \mathrm{rpm}$ (in the constant-torque mode), and $\pm 2200 \mathrm{rpm}$ (in the constant-power mode) are shown in Figs. 8 and 9, 10 and 11, and 12 and 13 , respectively.

In this study, the MRAS synchronous speed identification scheme was also designed using the conventional PI-type adaptation mechanism, and the simulated and measured responses with $2 \mathrm{~N}-\mathrm{m}$ load for the steady-state speed command $\pm 1200 \mathrm{rpm}$ are respectively shown in Figs. 14 and 15 .

The percentage errors of the estimated rotor speed for the simulated and measured responses using the proposed speed estimation of adaptive SFVC IM drive scheme are respectively shown in Figs. 16 and 17.

From the simulated and measured results for different operation conditions shown in Figs. 8-13, the rotor speed was accurately estimated. In addition, better responses of the stator current and electromagnetic torque were attained, and the estimated synchronous angle position and the circular shape of the estimated stator flux locus verified the exactness of the coordinate transformation between synchronous and stationary frames. These results show that the desired performance can be achieved using the proposed speed estimation of adaptive SFVC IM drive based on the PSO algorithm. Comparing Figs. 10 and 11 with Figs. 14 and 15, 
(a)

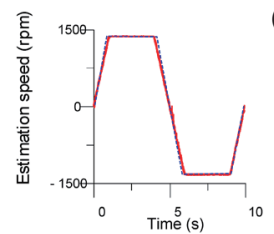

(b)

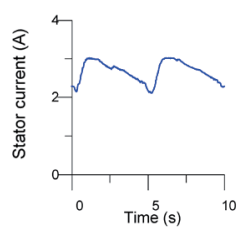

(c)

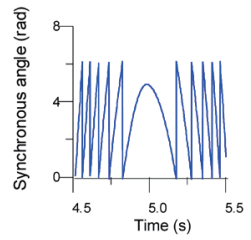

(d)

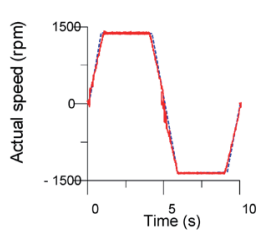

(e)

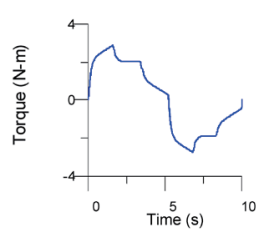

(f)

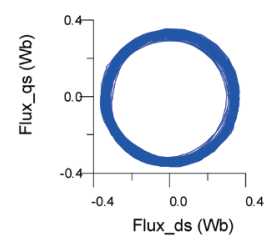

Fig. 14. (Color online) Simulated responses of the conventional PI-type adaptation mechanism of speed estimation of adaptive SFVC IM drive with $2 \mathrm{~N}$-m load for steady-state speed command $\pm 1200 \mathrm{rpm}$. (a) Command speed (blue line) and estimated rotor speed (red line), (b) command speed (blue line) and actual rotor speed (red line), (c) stator current, (d) electromagnetic torque, (e) estimated synchronous angle position, (f) stator flux locus.

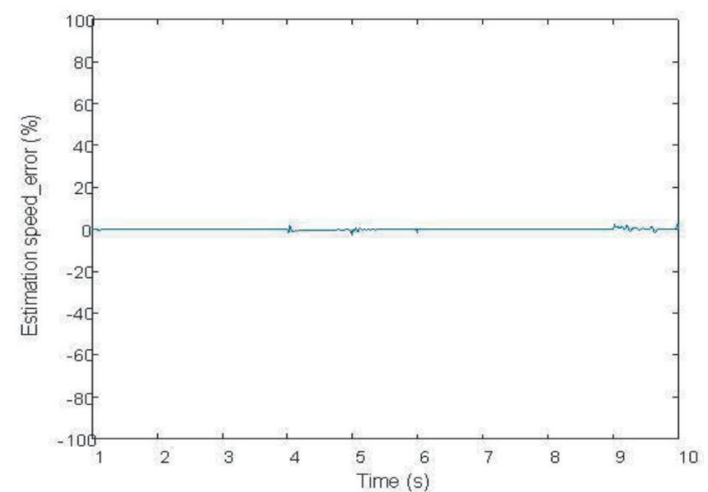

Fig. 16. (Color online) Simulated responses of the estimation percentage errors between actual and estimation speed for the adaptive SFVC IM drive.

(a)

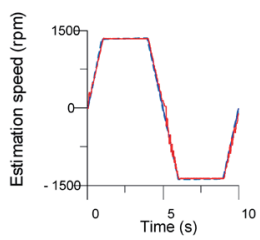

(b)

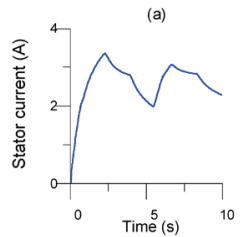

(c)

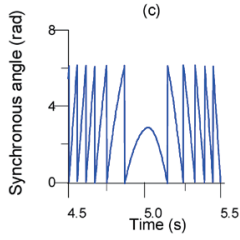

(d)

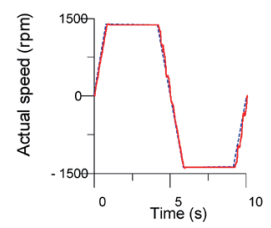

(e)

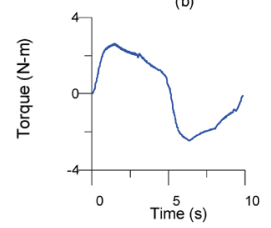

(f)

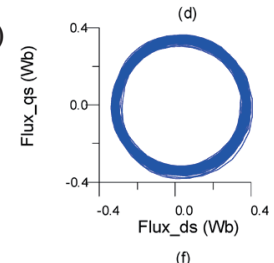

Fig. 15. (Color online) Measured responses of the conventional PI-type adaptation mechanism of speed estimation of adaptive SFVC IM drive with $2 \mathrm{~N}-\mathrm{m}$ load for steady-state speed command $\pm 1200 \mathrm{rpm}$. (a) Command speed (blue line) and estimated rotor speed (red line), (b) command speed (blue line) and actual rotor speed (red line), (c) stator current, (d) electromagnetic torque, (e) estimated synchronous angle position, (f) stator flux locus.

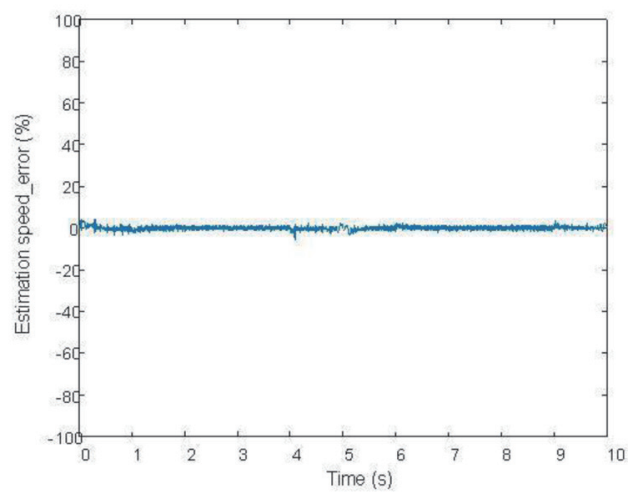

Fig. 17. (Color online) Measured responses of the estimation percentage errors between actual and estimation speed for the adaptive SFVC IM drive.

it can be concluded that the adaptation mechanism with the PSO algorithm is better than the conventional one with PI-type mechanism. According to Figs. 16 and 17, for the simulation and measurement responses, the estimation percentage errors between the actual and estimated speeds are approximately 0.4 and $0.8 \%$, respectively. 


\section{Conclusions}

In this study, an adaptive synchronous speed on-line estimation scheme based on the inertia weight PSO algorithm was proposed for the speed estimation of an SFVC IM drive. The MRAS synchronous speed estimation scheme was established on the basis of the reactive power of an IM, and the estimated rotor speed was acquired by subtracting the estimated slip speed from the estimated synchronous speed. The adaptation mechanism of MRAS was designed using the inertia weight PSO algorithm. The stator current signal measurement carried out to implement this adaptive speed estimation SFVC IM drive is provided by Hall effect current sensors. The operation speed can be extended to the constant-power mode using the field-weakening technique. Both the simulation and experiment results (including the estimated rotor speed, stator current, electromagnetic torque, estimated synchronous angle position, and stator flux locus) confirmed that superior performance was achieved in terms of acceleration, steady-state operation, and braking operation at different reversal speeds.

\section{References}

1 Y. C. Luo and Y. H. Chen: Intell. Fuzzy Syst. 36 (2019) 1215. https://doi.org/ 10.1177/1461348418824942

2 M. Comanescu and P. S. Altoona: Proc. IEEE Sensorless Control for Electrical Drives (IEEE, 2017) 213. https://doi.org/10.1109/SLED.2017.8078452

3 M. S. Morey, V. B. Virulkar, and G. A. Dhomane: Proc. Int. Conf. Electrical, Electronics, and Optimization Techniques (IEEE, 2016) 3422. https://doi.org/10.1109/ICEEOT.2016.7755340

4 S. J. Purti, R. Kumar, and S. Das: Proc. Int. Conf. Computer, Control and Communication (IEEE 2016) 1. https://doi.org/10.1109/IC4.2015.7375583

5 Y. C. Luo, Y. H. Chen, and Y. P. Kuo: Sens. Mater. 31 (2019) 165. https://doi.org/10.18494/SAM.2019.2020

6 Y. C. Luo and C. L. Tsai: Low Freq. Noise Vibr. Act. Control 38 (2019) 1220. https://doi. org $/ 10.1177 / 1461348418784187$

7 A. N. Smith, S. M. Gadoue, and J. W. Finch: IEEE Trans. Energy Converse 31 (2016) 270. https://doi. org/10.1109/TEC.2015.2480961

8 I. Vicente, A. Endeman, X. Garin, and M. Brown: IET Control Theory Appl. 4 (2010) 993. https://doi. org/10.1049/iet-cta.2008.0506

9 A. Pal, S. Das, and A. K. Chattopadhyay: IEEE Trans. Power Electron. 33 (2018) 5131. https://doi.org/10.1109/ TPEL.2017.2657648

10 G. Tarchała and O. K. Teresa: IEEE Trans. Ind. Electron. 65 (2018) 6936. https://doi.org/10.1109/ TIE.2018.2795518

11 M. Farasat, A. M. Trzynadlowski, and M. S. Fadali: IET Elec. Sys. Transp. 4 (2014) 122. https://doi. org/10.1049/iet-est.2014.0018

12 K. L. Shi, T. F. Chan, Y. K. Wong, and S. L. Ho: IEEE Trans. Ind. Electron. 49 (2002) 124. https://doi. org $/ 10.1109 / 41.982256$

13 S. Jafarzadeh, C. Lascu, and M. S. Fadali: IEEE Trans. Ind. Appl. 49 (2013) 92. https://doi.org/10.1109/ TIA.2012.2229251

14 C. H. Liu: Control of AC Electrical Machines (Tunghua, Taipei, 2008) (in Chinese).

15 Y. C. Luo and Z. S. Ke: Smart Sci. 2018 (2018) 1. https://doi.org/10.1080/23080477.2018.1451207

16 J. Kennedy and R. Eberhat: Proc. IEEE Int. Conf. Neural Networks (IEEE, 1995) 1942. https://doi.org/10.1109/ ICNN.1995.488968

17 J. C. Bansal, H. Sharma, S. S. Jadon, and M. Clerc: Memetic Comput. 6 (2014) 31. https://doi.org/10.1007/ s12293-013-0128-0

18 Y. C. Luo, C. L. Tsai, and Y. P. Kuo: Sens. Mater. 30 (2018) 845. https://doi.org/10.18494/SAM.2018.1788

19 H. Williams and M. Bishop: Algorithm 7 (2014) 206. https://doi.org/10.3390/a7020206

20 M. Dorigo, G. D. Caro, and L. M. Gambardella: Artif. Life 5 (1999) 137. https://doi. org $/ 10.1162 / 106454699568728$

21 Y. C. Luo and W. A. Huang: J. Low Freq. Noise Vibr. Act. Control 38 (2019) 692. https://doi. org/10.1177/1461348418824942 


\section{About the Authors}

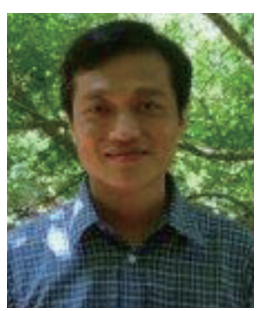

Yung-Chang Luo received his M.S. and Ph.D. degrees from National Taiwan University of Science and Technology, Taipei, Taiwan, ROC, in 1991 and 2000, respectively. He is currently a professor in the Department of Electrical Engineering, National Chin-Yi University of Technology, Taichung, Taiwan, ROC. His current research interests include the speed estimation of ac motor drives, the front-end power factor correction of converters, and the design of microcontroller-based motor drives. (luoyc@ncut.edu.tw)

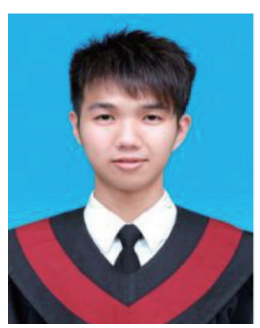

Sheng-Hong Pei was born in 1994. He is a master's student at the Department of Electrical Engineering, National Chin-Yi University of Technology, Taiwan. His research mainly focuses on FVC IM drives. (s0975719015@gmail.com)

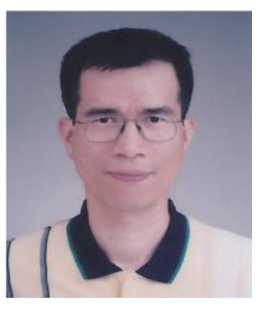

Ying-Piao Kuo received his B.S. degree in electrical engineering in 1985 from National Taiwan University of Science and Technology, Taipei, Taiwan, his M.S. degree in electrical engineering in 1989 from National Taiwan University, and his Ph.D. degree from National Taiwan University of Science and Technology, Taipei, Taiwan, in 2011. In 1989, he joined the National Chin-Yi University of Technology, Taichung, Taiwan, where he is currently an associate professor in the Department of Electrical Engineering. His current research interests include the design of switching-mode power supplies, partial discharge, and power system stability. (kuoyc@ncut.edu.tw)

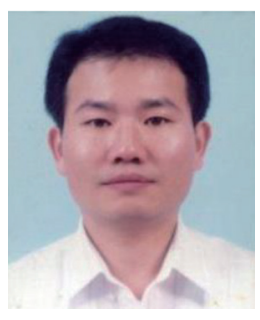

Cheng-Tao Tsai received his B.S. degree in electrical engineering in 1991 from Feng Chia University, Taichung, Taiwan, and his M.S. and Ph.D. degrees from National Chung Cheng University, Chia-Yi, Taiwan, in 2003 and 2008, respectively. Recently, he joined the National Chin-Yi University of Technology, Taichung, Taiwan, where he is currently a professor in the Department of Electrical Engineering. His current research interests include the design of switching-mode power supplies, power factor correction technology, and chargers for electric vehicles. (cttsai@ncut.edu.tw) 